\title{
Prevalence of Thyroid Disorders in Patients in Tertiary Care in South India: A Prospective Study
}

\author{
Ramesh Polasa ${ }^{1}$, Mahaswi Sirangi ${ }^{2}$ \\ ${ }^{1}$ Associate Professor, Department Of Pediatrics, Kakatiya Medical College, Mahatma Gandhi Memorial \\ Hospital, Warangal, Telangana, India-506002. \\ ${ }^{2}$ Intern, Department Of Pediatrics, Kakatiya Medical College, Mahatma Gandhi Memorial Hospital, Warangal, \\ Telangana, India-506002.
}

\begin{abstract}
Iodine is an important micro-nutrient required for human nutrition. Iodine deficiency disorders (IDDs) are one of the major worldwide public health problems of today which causes wide spectrum of disabilities. It includes impairment of reproductive functions, lowering of IQ levels in school age children, goiter, deaf mutism, mental defects, weakness and paralysis of muscles as well as lesser degree of physical dysfunction. Children below 12 years of age who visited the Pediatric Out-Patient Department (OPD) and inpatient department (IPD) of a tertiary care hospital in South India were included if they had clinical suspicion of thyroid dysfunction. Among the 48 patients enrolled in the study, 28 patients were male patients (58.33\%) and 20 patients were female patients $(41.66 \%)$. The most prevalent were patients with hypothyroidism, 47 (97.91\%). Hyperthyroidism patients were 1 (2.08\%). Age group between 0 to 3 years was found to be more in number with a percentage of $37.5 \%$. Thyroid hormones are unique in view of their important role in fetal and early neonatal brain development and also having actions on growth and development during the first two decades of life. The adverse effects of deprivation of thyroid hormone on the rapidly growing infantile brain have prompted the institution of neonatal screening for congenital hypothyroidism thus promoting an early intervention.
\end{abstract}

Keywords: Thyroid, Hypothyroidism, Pediatrics

\section{Introduction}

Iodine is an important micro-nutrient required for human nutrition. Iodine deficiency disorders (IDDs) are one of the major worldwide public health problems of today which causes wide spectrum of disabilities. It includes impairment of reproductive functions, lowering of IQ levels in school age children, goiter, deaf mutism, mental defects, weakness and paralysis of muscles as well as lesser degree of physical dysfunction ${ }^{[1]}$. Many studies conducted all over India had shown high prevalence of goiter ${ }^{[2-5]}$. A nationwide goiter survey revealed that out of 283 studied districts of 29 states and 04 Union Territories, 235 have prevalence of endemic goiter ${ }^{[6]}$. In an attempt to eliminate iodine deficiency and to comply with the international goal of Universal Salt Iodization (USI), compulsory iodization of all table salts was introduced in India in 1983. In June 1992 the National Goiter Control Programme was appropriately redesigned as "National Iodine Deficiency Disorders Control Programme (NIDDCP)", in recognition of the spectrum of disorders due to iodine deficiency. Optimal thyroid function is essential for normal growth and development in young population. Autoimmune thyroiditis is becoming increasingly prevalent in children all over the world, as evident from goiter surveys. Subjects with autoimmune thyroiditis manifest clinically as euthyroidism, sub-clinical hypothyroidism, and overt hypothyroidism. Presence of anti TPO ab predicts progressive thyroid failure consequently affecting growth of children. It was proposed to study the immunomodulatory effect of homoeopathic system of medicine in autoimmune thyroiditis, well in line with the priority area regarding research on the preventive and promotive aspects of AYUSH practices and therapies.

\section{Materials And Methods}

Children below 12 years of age who visited the Pediatric Out-Patient Department (OPD) and in-patient department (IPD) of a tertiary care hospital in South India were included if they had clinical suspicion of thyroid dysfunction. A prospective observational study was done from March 2014 to February 2015 and was screened. Inclusion criteria were newborns and children below 12 years with clinical features suggestive of thyroid disorders like prolonged jaundice in newborn, features of cretinism, goiter, physical and mental growth retardation, obesity, constipation etc. Patients who were on any medications known to alter the thyroid hormone status including patients already diagnosed with thyroid disorder on therapy and patient in whom an informed consent could not be obtained were excluded from the study. A total of 48 patients were recruited, 12 from OPD and 36 from IPD. Demographic data (age, sex, address) including family history of thyroid disorders, use of iodized salt, data related to symptoms suggestive of thyroid hypo- or hyper- function (eg. dry skin, lethargy, 
developmental delay, prolonged neonatal jaundice, constipation) were recorded. Vital parameters were recorded and complete systemic examination was done. Examination of the thyroid gland was done as per WHO guidelines ${ }^{[7]}$. Eye signs of hyperthyroidism, e.g. conjunctival chemosis lid retraction, exophthalmos, lid lag, external opthalmoplegia etc., were also looked for ${ }^{[8]}$. All the 48 children were tested for thyroid profile consisting of Tri-iodothyronin (T3), Thyroxin (T4) and Thyroid stimulating hormone (TSH) levels.

\section{Results}

Table 1 and Figure 1 show the Gender distribution of patients with thyroid disorders. Among the 48 patients enrolled in the study, 28 patients were male patients $(58.33 \%)$ and 20 patients were female patients $(41.66 \%)$.

\begin{tabular}{|l|l|l|l|}
\hline S. No & Gender & Number of Patients & Percentage \\
\hline 1 & Male & 28 & $58.33 \%$ \\
\hline 2 & Female & 20 & $41.66 \%$ \\
\hline
\end{tabular}

Table 1: Gender distribution of patients with thyroid disorders

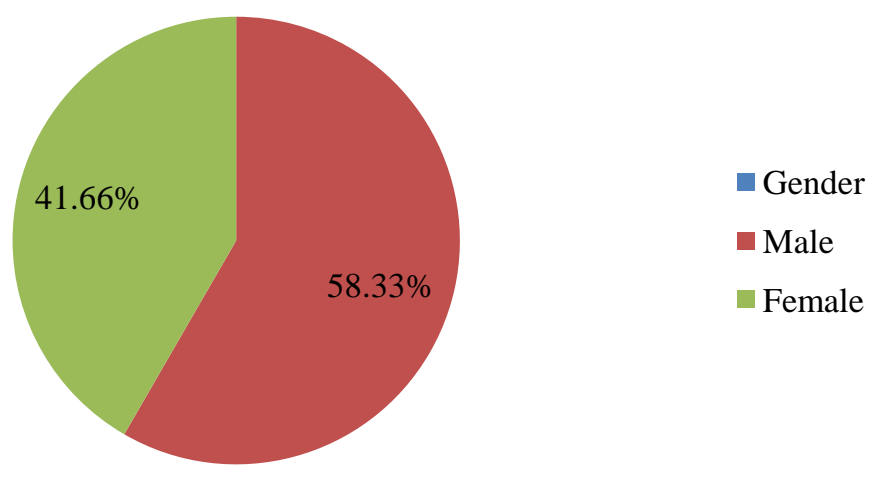

Figure 1: Gender distribution of patients with thyroid disorders

Table 2 and Figure 2 shows the prevalence of different types of thyroid disorders among the 48 patients. The most prevalent were patients with hypothyroidism, $47(97.91 \%)$. Hyperthyroidism patients were 1 $(2.08 \%)$.

\begin{tabular}{|l|l|l|l|}
\hline \multicolumn{1}{|c|}{ S.No } & Thyroid Disorder & No Of Patients & \% No Of Patients \\
\hline 1 & Hypothyroidism & 47 & $97.91 \%$ \\
\hline 2 & & & \\
\hline
\end{tabular}

Table 2: Prevalence of different types of thyroid disorders

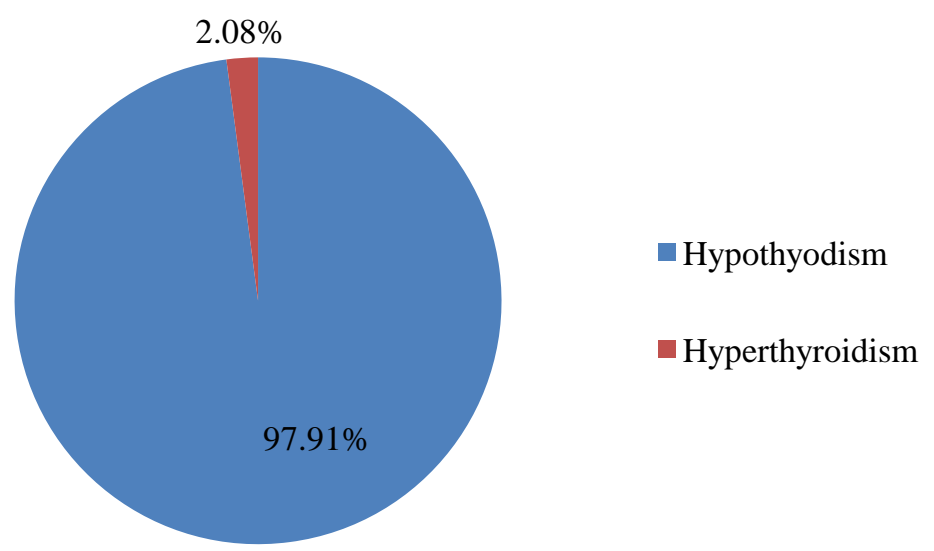

Figure 2: Prevalence of different types of thyroid disorders 
Table 3 and Figure 3 shows age wise distribution of thyroid disorders among the 48 patients. Age group between 0 to 3 years was found to be more in number with a percentage of $37.5 \%$.

\begin{tabular}{|l|l|l|l|}
\hline S. No & Age & Number of Patients & Percentage \\
\hline 1 & 0-3 years & 18 & $37.5 \%$ \\
\hline 2 & 4-6years & 14 & $29.16 \%$ \\
\hline 3 & 7-9 years & 10 & $20.83 \%$ \\
\hline 4 & 10-12 years & 6 & $12.5 \%$ \\
\hline
\end{tabular}

Table 3: Age wise distribution of thyroid disorders

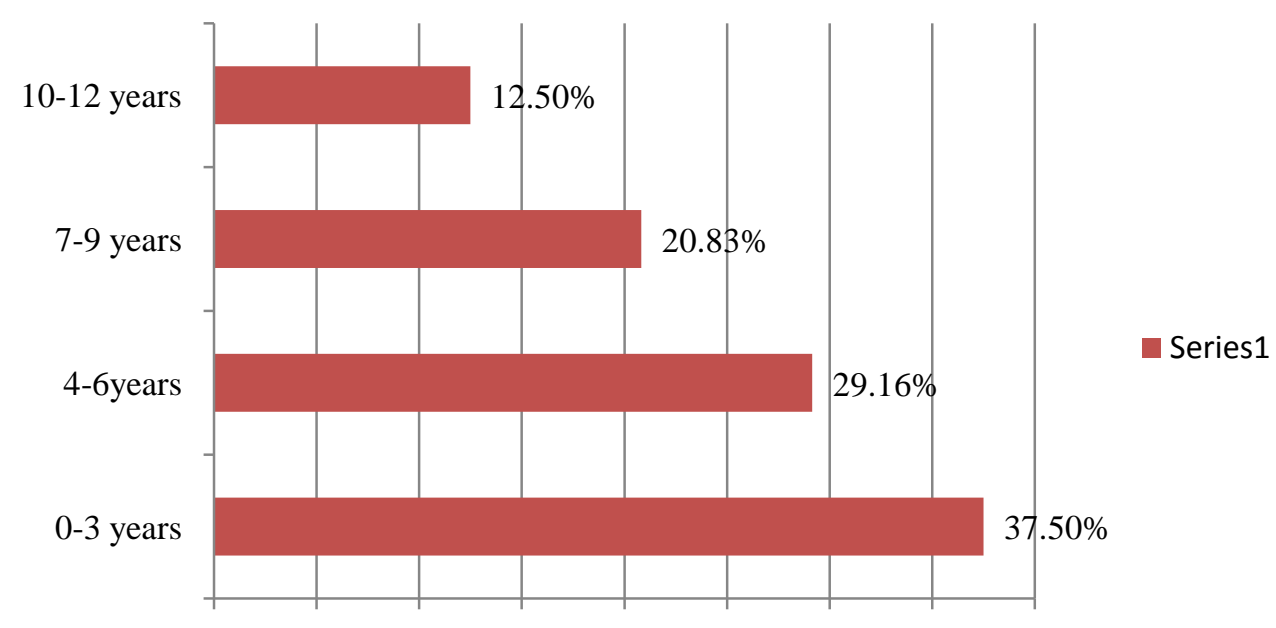

0.00\% 5.00\% 10.00\%15.00\%20.00\%25.00\%30.00\%35.00\%40.00\%

Figure 3: Age wise distribution of thyroid disorders

Table 4 and Figure 4 shows the presence of symptoms associated with hypothyroidism prolonged neonatal jaundice was found to be more in number with $20.83 \%$.

\begin{tabular}{|l|l|l|l|}
\hline S. No & Symptoms & Number of Patients & Percentage \\
\hline 1 & Dry skin & 6 & $12.5 \%$ \\
\hline 2 & Lethargy & 8 & $16.66 \%$ \\
\hline 3 & Developmental delay & 2 & $4.16 \%$ \\
\hline 4 & Prolonged neonatal jaundice & 10 & $20.83 \%$ \\
\hline 5 & Constipation & 9 & $18.75 \%$ \\
\hline
\end{tabular}

Table 4: Presence of symptoms associated with hypothyroidism

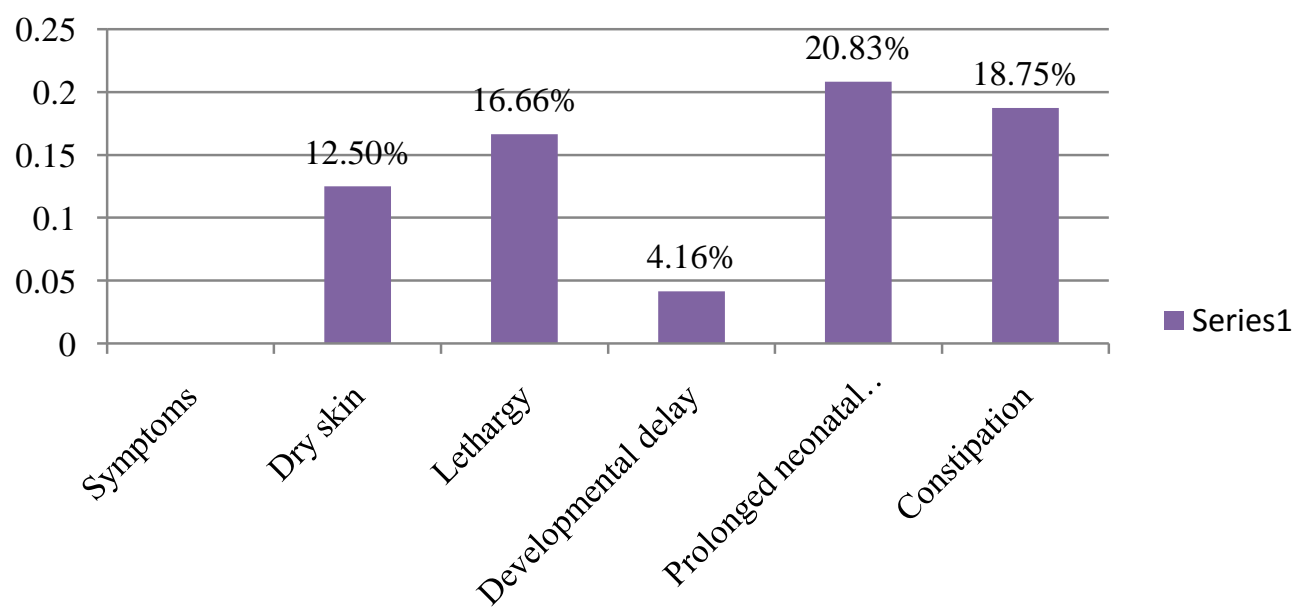

Figure 4: Presence of symptoms associated with hypothyroidism 


\section{Conclusion}

Thyroid hormones are unique in view of their important role in fetal and early neonatal brain development and also having actions on growth and development during the first two decades of life. The adverse effects of deprivation of thyroid hormone on the rapidly growing infantile brain have prompted the institution of neonatal screening for congenital hypothyroidism thus promoting an early intervention. But in the absence of similar services in India, many cases of hypothyroidism remain unrecognized and may cause havoc in the developing brain. The findings of this study underscore the need to adopt strategies to evaluate children from our community for disorders of thyroid gland.

\section{Reference}

[1]. Vir. S. Universal iodization of salt: A mid decade goal. In: Sachdev HPS and Choudhary (Eds.) Nutrition in Children - Developing country concerns. New Delhi: Cambridge Press, 1994; p. 525-535

[2]. Directorate General of Health Services (DGHS). Ministry of Health and Family Welfare, Govt. of India. Policy Guidelines on National Iodine Deficiency Disorders Control Programme. New Delhi; 2003; p. 1-10.

[3]. ICMR. Epidemiological survey of endemic goiter and endemic cretinism. New Delhi: Indian Council of Medical Research; 198

[4]. Indicators for Assessing Iodine Deficiency Disorders and their Control Programmes. Report of a Joint WHO/ UNICEF/ICCIDD Consultation, Geneva: World Health Organization; 1992. p. 22-29.

[5]. Control of iodine deficiency through safe use of iodized salt. ICMR Bull. 1996; 26: 41-46.

[6]. NIHFW. National iodine deficiency disorders control Programme. National Health Programme Series 5. National Institute of Health and Family Welfare, New Delhi: 2003; p. 99.

[7]. 7.World Health Organization, International Council for Control of Iodine Deficiency Disorders, UNICEF. Indicators for assessing iodine deficiency disorder and their control through salt iodization. Geneva: World Health Organization. 1994 , pp 14.

[8]. Perros P, Neoh C, Dickinson J. Thyroid eye disease. BMJ. 2009;338:b560. 